\title{
PERFORMANCE TESTS OF INDUSTRIAL PROTOTYPE SUBCOOLING HELIUM HEAT EXCHANGERS FOR THE LARGE HADRON COLLIDER
}

\author{
P. Roussel ${ }^{1}$, A. Bézaguet ${ }^{2}$, H. Bieri ${ }^{3}$, R. Devidal ${ }^{4}$, B. Jager ${ }^{1}$, \\ R. Moracchioli ${ }^{5}$, P. Seyfert ${ }^{1} \&$ L. Tavian ${ }^{2}$. \\ ${ }^{1}$ DSM/DRFMC/SBT, CEA, F-38054 Grenoble Cedex 9 (France) \\ ${ }^{2}$ LHC Division, CERN, CH-1211 Geneva 23 (Switzerland) \\ ${ }^{3}$ Romabau, Fohlenweide, CH-8570 Weinfelden (Switzerland) \\ ${ }^{4}$ SNLS, ZI les Condamines, F-38160 St Romans (France) \\ ${ }^{5}$ DATE, La Condamine, F-38770 La Motte d'Aveillans (France)
}

\begin{abstract}
The superconducting magnets of the Large Hadron Collider (LHC) will be cooled at $1.9 \mathrm{~K}$ by distributed cooling loops working with saturated two-phase helium, and supplied with cold supercritical helium. In order to minimise the vapour fraction produced in the final expansion, counter-flow heat exchangers will be needed. Such heat exchangers, of compact design, featuring low-pressure drop and handling very low-pressure vapour, are non-standard products, may be of various designs, and built according to various technologies. In order to qualify potential suppliers for the 250 -unit series production, CERN has procured $5 \mathrm{~g} / \mathrm{s}$ prototype subcooling helium heat exchangers from four industrial companies, based on different construction principles, and tested them in collaboration with CEA Grenoble where a dedicated test station has been built. After recalling the common functional specification, as well as the main design features of the prototypes and test station, comparative performance results are presented, and conclusions drawn as concerns future series production for the LHC.
\end{abstract}

\section{INTRODUCTION}

The superconducting magnets of the LHC [1] under construction at CERN will be cooled at $1.9 \mathrm{~K}$ by distributed cooling loops working with saturated two-phase helium, and supplied with cold supercritical helium. In order to minimise the vapour fraction produced in the final expansion, counter-flow heat exchangers will be needed [2]. 
These 250 subcooling heat exchangers will be integrated in the LHC Cryogenic Distribution Line [3] thus requiring high reliability and good efficiency. To qualify suppliers for the series production, a market survey describing the supply and imposing selection criteria was sent to European industry. Following this survey, a price enquiry has been sent out to 8 firms for the delivery of prototypes and 4 firms have been selected for supplying 2 prototype heat exchangers each. During production one firm failed and has been rejected at the stage of factory tests, which included checks of mechanical integrity and tightness. Consequently, only 3 firms, DATE (FR), Romabau (CH) and SNLS (FR) have delivered prototypes of different technologies for extensive cryogenic testing. The final qualification for the series production was depending on the results of these cryogenic tests at different operating conditions carried out in 1999 and 2000 at CEA-Grenoble. A dedicated test station [4] was set up, in the framework of the collaboration between CEA and CERN for the construction of the LHC.

This paper recalls the main technical specification imposed by CERN, presents the technologies chosen by the firms and compares the measurement results obtained during these qualification tests.

\section{MAIN TECHNICAL SPECIFICATION}

\section{Subcooling Heat Exchanger Performances}

These heat exchangers have to subcool by counter-flow the incoming flow of supercritical (SC) helium, using the very low-pressure (VLP) vapour returning from the magnet cooling loop at around $1.8 \mathrm{~K}$. Figure 1 shows the flow scheme of the heat exchanger circuits. To fulfil CERN specifications, the heat exchangers must comply with constraints on thermal efficiency and pressure drop in the different streams.

The heat exchanger has to operate at nominal or reduced capacity. Table 1 gives the imposed inlet conditions as well as the functional requirements which have to be fulfilled by the heat exchanger in steady-state operation mode for which the mass-flow in the two streams is equal.

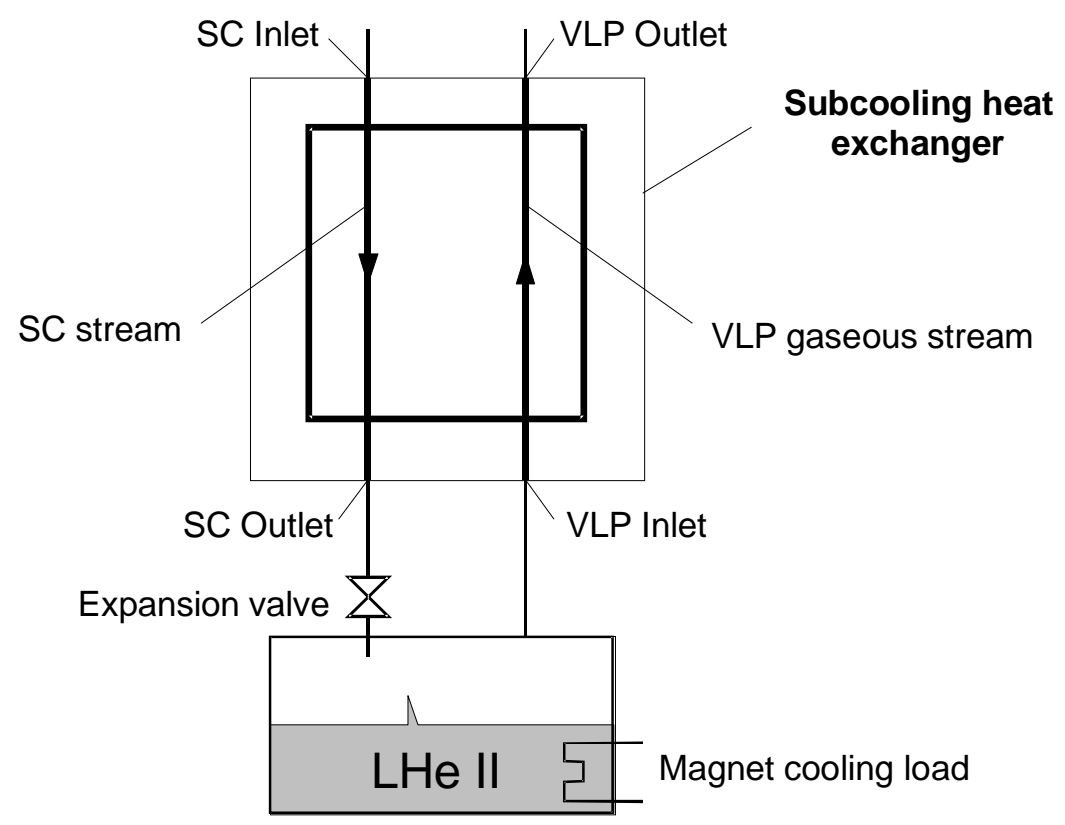

FIGURE 1: Subcooling heat exchanger flow-scheme 
TABLE 1. Steady-state operation conditions

\begin{tabular}{|c|c|c|c|c|}
\hline \multirow{2}{*}{ Conditions } & & \multirow{2}{*}{ Units } & \multicolumn{2}{|c|}{ Capacity } \\
\hline & & & Nominal & Reduced \\
\hline \multirow{6}{*}{$\begin{array}{l}\text { Process points } \\
\text { Imposed by CERN }\end{array}$} & Inlet SC pressure & {$[\mathrm{kPa}]$} & 240 to 360 & 240 to 360 \\
\hline & Inlet SC temperature & {$[\mathrm{K}]$} & 4.9 & 4.9 \\
\hline & Inlet SC flow-rate & {$[\mathrm{g} / \mathrm{s}]$} & 4.5 & 1.5 to 4.5 \\
\hline & Inlet VLP pressure & {$[\mathrm{kPa}]$} & 1.64 & 1.64 \\
\hline & Inlet VLP temperature & {$[\mathrm{K}]$} & 1.8 & 1.8 \\
\hline & Inlet VLP flow-rate & {$[\mathrm{g} / \mathrm{s}]$} & 4.5 & 1.5 to 4.5 \\
\hline \multirow{3}{*}{$\begin{array}{l}\text { To be fulfilled by } \\
\text { the heat exchanger }\end{array}$} & Outlet SC temperature & {$[\mathrm{K}]$} & $\leq 2.2$ & $\leq 2.2$ \\
\hline & VLP stream pressure drop & {$[\mathrm{Pa}]$} & $\leq 100$ & $\leq 100$ \\
\hline & SC stream pressure drop & {$[\mathrm{kPa}]$} & $\leq 20$ & $\leq 20$ \\
\hline
\end{tabular}

\section{Space and Integration Constraints}

As the subcooling heat exchangers will be integrated in the LHC Cryogenic Distribution Line, they must fulfil several constraints. The heat exchanger shall be placed vertically or inclined at an angle of $10^{\circ}$ with respect to the vertical, with the warmer end located at the top. The overall height must be less than $450 \mathrm{~mm}$ and the standard crosssection must not exceed $120 \mathrm{~mm} \times 120 \mathrm{~mm}$. At the header locations, an enlarged crosssection of $160 \mathrm{~mm} \times 160 \mathrm{~mm}$ may be accepted. Figure 2 shows the maximum overall size of the heat exchanger and defines the location of the inlet and outlet piping.

The heat exchanger inlet and outlet piping are cylindrical tubes in austenitic stainless steel, such as AISI 304L or equivalent. The interface pipe inner diameters of are $60 \mathrm{~mm}$ for the VLP interfaces and $10 \mathrm{~mm}$ for the SC ones. For cryogenic test purpose, Kenol ${ }^{\circledR}$ flanges with metallic seals must be part of the delivery.

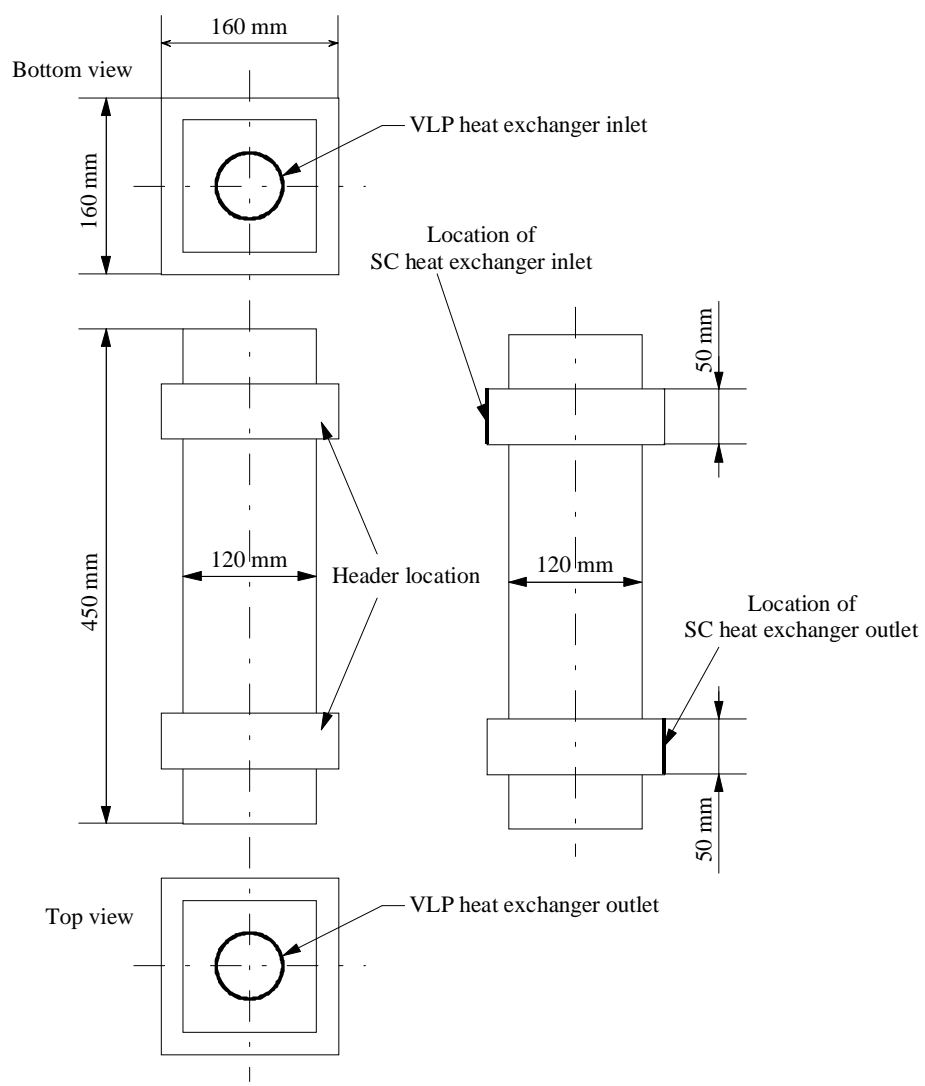

FIGURE 2. Maximum overall size of heat exchanger 


\section{DESIGN FEATURES FOR THE DIFFERENT TECHNOLOGIES APPLIED}

\section{Stainless Steel Plate Heat Exchanger}

This heat exchanger type has been developed by the DATE company. They consist in a stack of 50 stainless steel plates oriented parallel to the flow directions. The plates are $0.6 \mathrm{~mm}$ thick and permit a good thermal contact between the streams while keeping low longitudinal conduction. The VLP channels and SC channels are respectively $1.0 \mathrm{~mm}$ and $0.6 \mathrm{~mm}$ wide. The length of the plates is $250 \mathrm{~mm}$. The channel width is kept constant thanks to small mechanical deformation regularly scattered on the plates and obtained by embossing. The stack of plates is then TIG welded. The flow across the VLP is laminar. The trade-off between pressure drop and thermal performances depends on the VLP channel width, the number of plates and their length. Figure 3 shows the stainless steel stack during the construction phases and a view of a completed heat exchanger.

During manufacturing and after a pressure drop measurement with air, the first two heat exchangers were rejected by DATE who decided to re-design two new prototypes.

\section{Perforated Copper Plate Heat Exchangers}

This heat exchanger type has been developed by CEA-Grenoble [5] and manufactured by the SNLS company. They are made up of a stack of high thermal conductivity perforated copper plates, alternating with low thermal conductivity stainless steel spacers vacuum brazed using silver brazing. The plates are transverse to the flows. For this cryogenic application, the thickness of the perforated plates, the diameter of the flow passages and the height of the gap between adjacent plates are usually small and roughly equal in magnitude $(\sim 0.6 \mathrm{~mm})$. This ensures a high surface area density (better than $15000 \mathrm{~m}^{2} / \mathrm{m}^{3}$ ) and enhances convective heat transfer between the plates and fluid streams. The low thermal conductivity spacers are crucial in reducing longitudinal conduction which otherwise would spoil the high potential efficiency of that type of heat exchanger. For the LHC application the number of plates has been adjusted to 125 (same number of spacers, plus one) and the VLP flow is split into five channels made of slots, while the SC flow is divided into four channels consisting of $0.5 \mathrm{~mm}$ diameter holes. Figure 4 shows a SNLS copper plate before brazing and a view of the completed heat exchanger.

Two first SNLS prototypes were built and cryogenically tested. They were rejected because of too high pressure drop (factor 2) at nominal capacity. After analysis of the results, a new prototype (SNLS \#3) was designed and built. The hydraulic and thermal performance of this third prototype are presented hereafter.
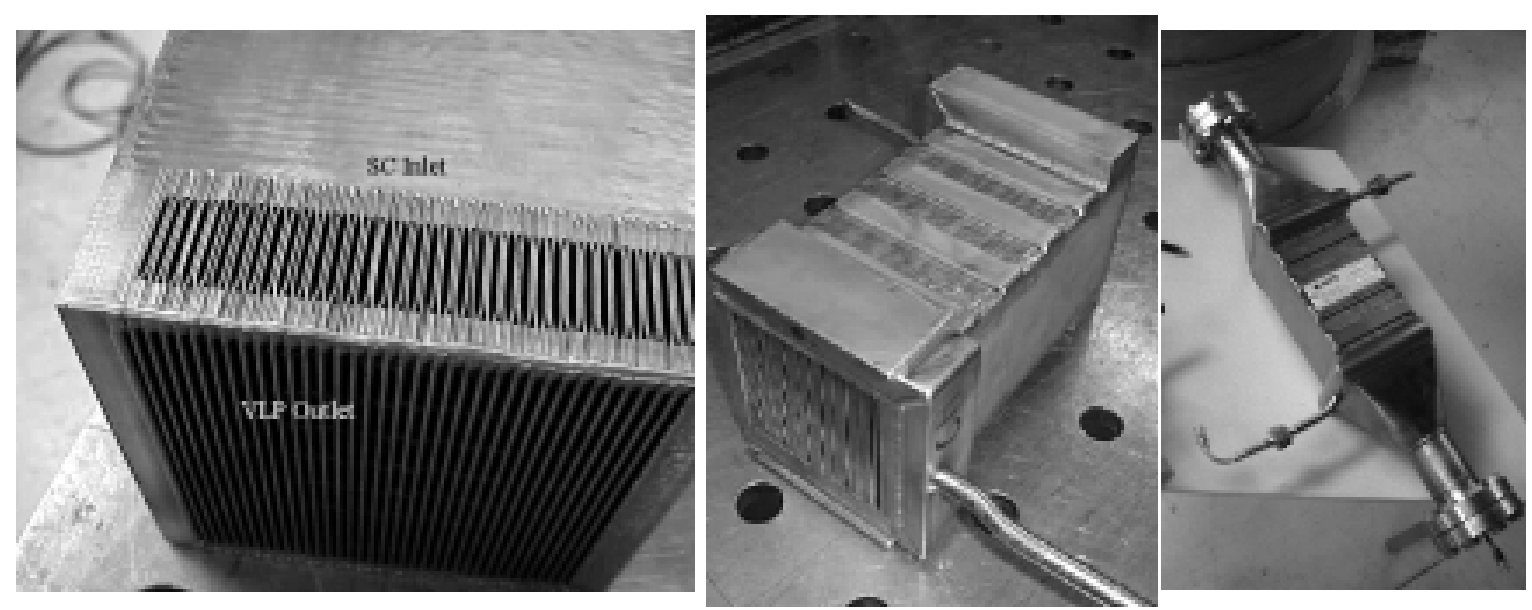

FIGURE 3. Stainless steel stack during construction phases and view of a completed DATE heat exchanger 

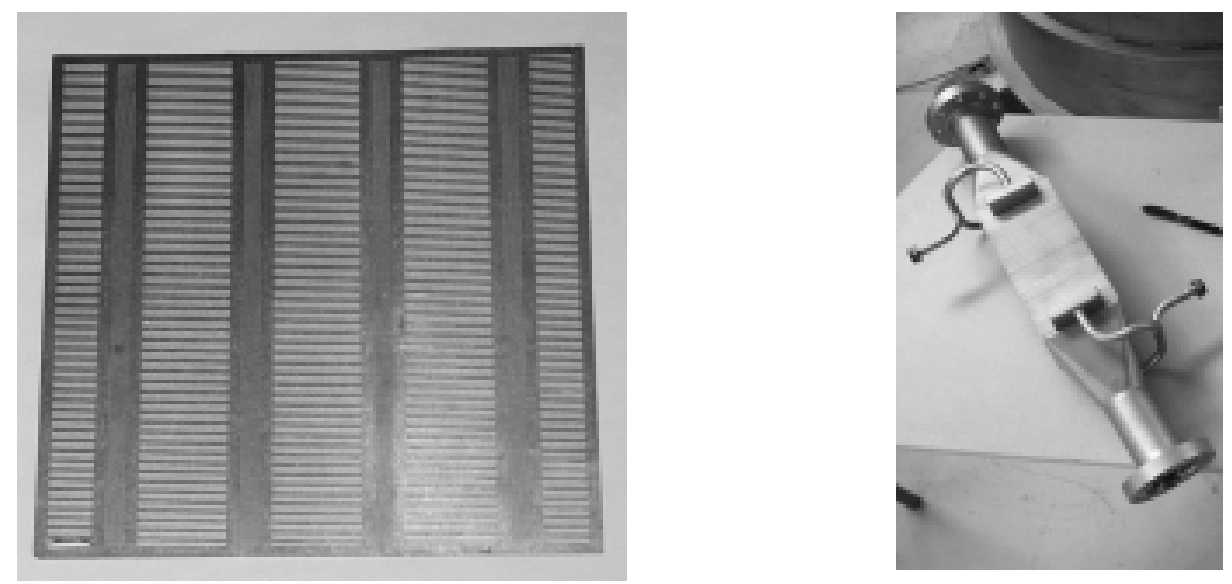

FIGURE 4. SNLS perforated copper plate with holes (SC channels) and slots (VLP channels), and completed heat exchanger.

\section{Coiled Tube Heat Exchanger}

This heat exchanger type has been developed and manufactured by Romabau. In this construction the SC stream is composed of a bank of twenty tubes of $2.5 \mathrm{~mm}$ outer diameter with a thickness of $0.15 \mathrm{~mm}$ and lengths varying from $7.5 \mathrm{~m}$ to $12.3 \mathrm{~m}$. The tubes are wound in 9 parallel coils in diameters varying from $52 \mathrm{~mm}$ to $113 \mathrm{~mm}$ and immersed in the VLP stream for efficient exchange. To avoid parasitic convective exchange inside the supporting internal cylinder, it is filled with stacks of multi-layer insulation. The tube extremities are welded to the header collectors by micro-plasma welding. The spacing between tubes and coils is precisely adjusted with 4 rows of stainless steel combs equally distributed at $90^{\circ}$ from each other.

The trade-off between pressure drop and thermal performances is a result of the length, number and arrangement of the tubes. Figure 5 shows the SC tube coils after assembly and a view of a completed heat exchanger.

During factory test, of the Romabau prototype B, a leak was discovered between one tube and the VLP stream. The leaky tube was blocked by welding in order to restore the leak tightness. The consequence on thermal performance was measured during cryogenic tests.
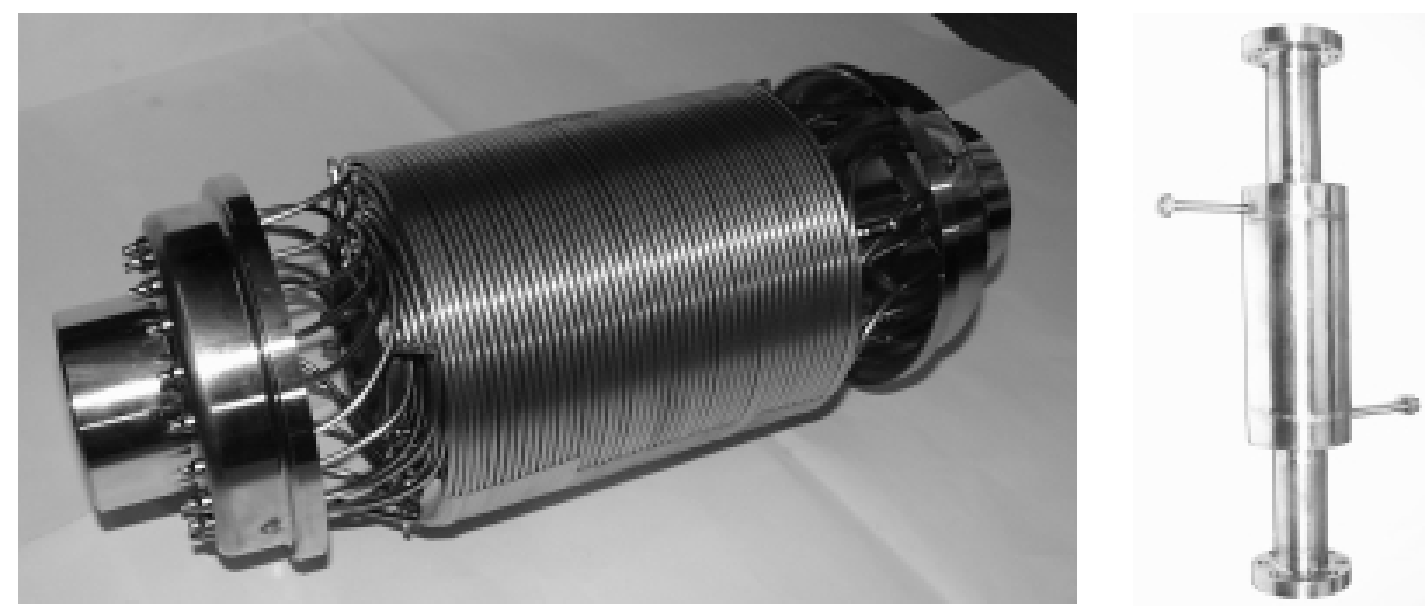

FIGURE 5. SC tube coils after assembly and view of a completed Romabau heat exchanger 


\section{EXPERIMENTAL RESULTS}

A dedicated test bench was set up at CEA-Grenoble. This facility allowed to perform cryogenic tests under nominal and reduced capacity. Thanks to highly accurate temperature and pressure drop measurements the thermal and hydraulic performance of the heat exchangers could be estimated precisely.

\section{Hydraulic Performance at Nominal and Reduced Capacity}

Pressure drop at low temperature at nominal capacity was one of the main requirement of CERN in order to optimise the global cryogenic efficiency. The technical specification imposed a maximum pressure drop in the VLP stream of $100 \mathrm{~Pa}$.

Figure 6 shows the measured pressure drop in the VLP stream as a function of the mass-flow for the different heat exchangers prototypes. All of the tested heat exchangers fulfilled the requirements of the technical specification. However, some variation could be observed depending of the technology used. With respect to the maximum allowed pressure drop for nominal flow, the DATE heat exchangers have a hydraulic margin of 3 to $15 \%$. For the SNLS prototype, a $30 \%$ margin remains and for the Romabau prototypes, a large margin of 56 to $59 \%$ was measured. At reduced capacity, the pressure drop decreases with mass-flow to a power slightly lower than 2 .

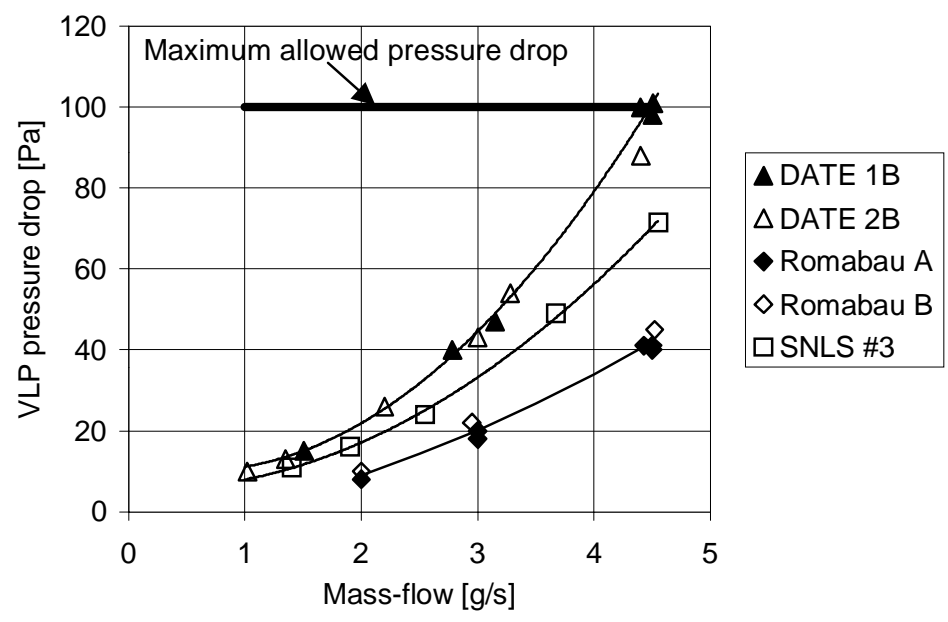

FIGURE 6. VLP pressure drop measurements versus mass-flow at nominal and reduced capacities

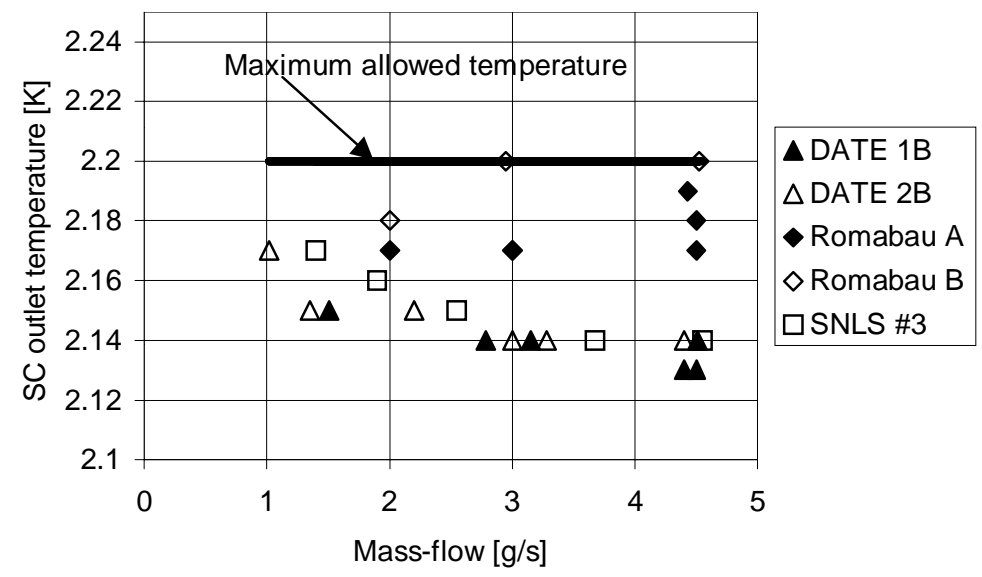

FIGURE 7. SC Subcooling outlet temperature versus mass-flow 


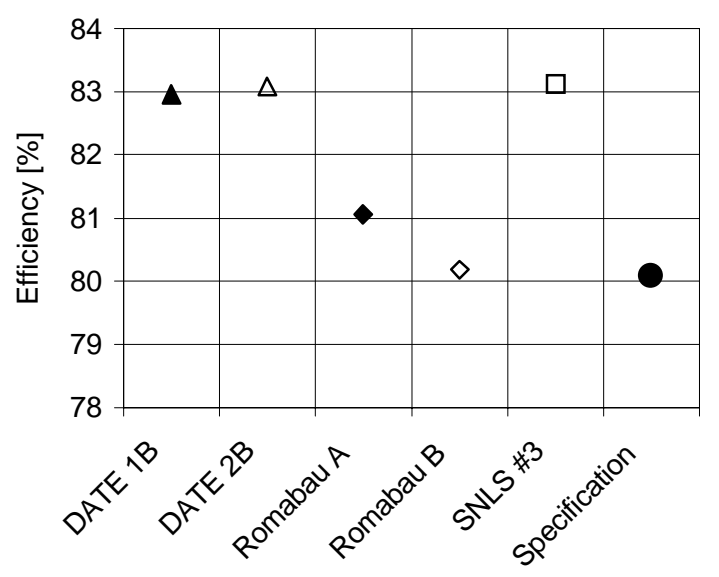

FIGURE 8. Calculation of thermal efficiencies at nominal capacity

\section{Thermal Performance at Nominal and Reduced Capacity}

Figure 7 shows the subcooling temperature reached at the SC outlet as a function of mass-flow for the different prototypes. All heat exchangers were able to subcool the SC outlet temperature below $2.2 \mathrm{~K}$ and fulfilled the technical specification. However, the Romabau B prototype reached the upper limit and obtained a different performance than the Romabau A, a difference explained by the blocking of one of the twenty tube of the SC stream following repair of the leak. One can deduce by comparison that this leaves a margin of $5 \%$ on the thermal performance for the Romabau A.

Figure 8 shows the heat exchanger efficiencies as determined from the cold test measurements. At nominal capacity, CERN's technical specification corresponds to an efficiency of $80 \%$ and it can be noted that all prototypes reached this value. The results obtained for reduced capacities do not give any advantage to one of the technologies as the efficiencies obtained are quite similar for the three different types of heat exchangers.

The DATE and SNLS prototypes have efficiency close to $83 \%$. For these heat exchangers, the SC outlet temperature reached the lambda line below which helium become superfluid. The bottom part of the heat exchangers is therefore partially shunted by the high conductivity of superfluid helium. Consequently, the tests underestimate the real efficiency and the margin with respect to the heat exchange area. Concerning the Romabau prototypes, the lambda line is not reached and the measured efficiencies correspond to the real ones. However, these prototypes have a high hydraulic margin and it seems possible by changing slightly the design, to better balance the thermal and hydraulic margins.

One way to better assess the thermal performance of the heat exchangers is to increase the SC inlet temperature in order to obtain a SC outlet condition above the lambda line. This test has been made on the DATE prototypes. Table 2 gives the new operating conditions and calculated efficiencies which increase by 3 to 7 points with respect to nominal conditions.

TABLE 2. Efficiency of the DATE heat exchangers in off-design operating mode.

\begin{tabular}{cc|ccc|ccc|c}
\hline $\begin{array}{c}\text { DATE } \\
\mathrm{N}^{\circ}\end{array}$ & $\begin{array}{c}\text { Mass- } \\
\text { flow } \\
{[\mathrm{g} / \mathrm{s}]}\end{array}$ & $\begin{array}{c}\mathrm{T} \text { inlet } \\
{[\mathrm{K}]}\end{array}$ & $\begin{array}{c}\text { SC Stream } \\
\mathrm{T} \text { oulet } \\
{[\mathrm{K}]}\end{array}$ & $\begin{array}{c}\mathrm{P} \text { inlet } \\
{[\mathrm{kPa}]}\end{array}$ & $\begin{array}{c}\mathrm{T} \text { inlet } \\
{[\mathrm{K}]}\end{array}$ & $\begin{array}{c}\text { VLP stream } \\
\mathrm{P} \text { inlet } \\
{[\mathrm{kPa}]}\end{array}$ & $\begin{array}{c}\mathrm{DP} \\
{[\mathrm{Pa}]}\end{array}$ & $\begin{array}{c}\text { Efficiency } \\
{[\%]}\end{array}$ \\
\hline $1 \mathrm{~B}$ & 4.7 & 5.78 & 2.19 & 359 & 1.83 & 1.60 & 160 & 90 \\
$2 \mathrm{~B}$ & 4.6 & 5.80 & 2.61 & 341 & 1.81 & 1.57 & 186 & 86 \\
\hline
\end{tabular}




\section{CONCLUSION}

The tests performed on the prototype subcooling helium heat exchangers for the Large Hadron Collider have permitted to technically qualify three companies which will compete for the supply of 250 series units. The interesting point was that three different technologies were proposed, and succeeded to fulfil the technical specifications imposed by CERN. Depending on the manufacturer's design, the thermal and hydraulic margins are not equally distributed. The DATE prototypes have substantial thermal margin but a small hydraulic one. Inversely, the Romabau prototypes have significant hydraulic margin but a reduced thermal one. These two manufacturers have to try to better balance the margins by slightly changing the heat exchanger design for the series production. The margins of the SNLS prototype seem well balanced and no special re-design is needed.

For the series production, a call for tender was sent out in April 2001. The offers will be analysed during summer 2001 and the contract adjudication will be done in autumn 2001.

\section{ACKNOWLEDGEMENTS}

The authors wish to thank P. Bonnay and P. Nivelon for the valuable work performed during the operation of the test station at CEA Grenoble.

\section{REFERENCES}

1. Evans, L. The Large Hadron Collider Project In: Proc.ICEC16, Elsevier science, Oxford, UK (1997) 45:52.

2. Chorowski, M., Erdt, W., Lebrun, Ph., Riddone, G., Serio, L., Tavian, L., Wagner, U., van Weelderen, R., A Simplified Cryogenic Distribution Scheme for the Large Hadron Collider, Adv. Cryo. Eng. 43 (1998)

3. Erdt,W., Riddone,G. and Trant,R. The cryogenic distribution line for the LHC: Functional specification and conceptual design. In: CEC-ICMC'99.

4. Roussel, P., Jager, B. and Tavian, L., A Cryogenic Test Station For Subcooling Helium Heat Exchangers For LHC, ICEC18 Bombay India 2000.

5. Viargues, F., Claudet, G., and Seyfert, P. Construction and preliminary testing of perforated-plate heat exchangers for use in HeII refrigerators, ICEC15 Genova, Italy 1994. 